Health benefits
President Bush's
first budget favours
the life sciences
p134

\title{
Early signs of a thaw in Bush's attitude to global warming
}

Matthew Davis, Washington

US cabinet-level officials have started stressing the importance of tackling global warming, in what appears to mark a change of direction for the Bush administration. But some environmental groups remain cautious, saying it is too soon to say where Bush will stand on the issue.

The clearest sign of a policy shift came ronmental Protection Agency, who said last week that the government was serious about reducing carbon dioxide emissions.

In an interview with the television network CNN, Whitman said the "science is good on global warming" and, to the extent that carbon reductions will have an impact on global warming, "that's an important step to take". In other interviews, she mentioned the possibility of supporting legislation that limits carbon emissions from power plants.

This would be a marked shift in US policy. The 1997 Kyoto Protocol resulted in a promise by countries to reduce emissions by an average of 5\% from 1990 levels before 2012. But the United States has disagreed, with the from Christie Whitman, head of the Envi-

European Union (EU) in particular, as to how these reductions should be made. It has resisted reducing its own greenhouse-gas emissions in favour of such measures as planting trees or funding renewable energy projects in developing countries in return for carbon 'credits' against its own emissions.

The United States has disagreed with many countries on how much to offset carbon-absorbing biomass, such as forest and crops, against carbon emissions. This caused November's summit of 150 environment ministers in The Hague to end in deadlock (see Nature 408, 503-504).

Whitman said last week that the United States needed time to review its policies before the next talks on implementing the Kyoto Protocol in Bonn. The talks were due to resume in May, but have been pushed back to 16-27 July, in response to a request from the Bush administration.

The review does not necessarily mean the United States will turn its back on the Kyoto agreement (which Bush opposed during his campaign), Whitman told a G8 meeting of environment ministers last week in Italy.

\section{‘Cheap solution’ for climate change}

Quirin Schiermeier, Munich

Greenhouse-gas emissions could be stabilized cheaply, but inertia is impeding a change to energy-saving policies and technologies. This is the main conclusion of a new report by the Intergovernmental Panel on Climate Change (IPCC).

The IPCC cost-analysis of climate protection - or mitigation - policies estimates that industrialized countries could achieve the Kyoto Protocol's emission targets at a cost of no more than $2 \%$ of gross domestic product; perhaps much less.

"It will now be essential to convince governments that the costs of climate protection are significantly lower than some analysts argue," says Ogunlade Davidson, co-chair of the mitigation working group.

Some 200 lead authors from 120 countries contributed to the mitigation analysis. They conclude that the long-term economic benefits of climate protection will exceed the costs of using climate-friendly technologies, such as solar and wind power.

In two previous reports, the IPCC had provided strong scientific evidence for a rapid increase in mean global temperatures, and warned that global warming could have devastating consequences (see Nature 409, 445 and 971 ; 2001).

The new report makes few specific recommendations other than "careful consideration of the [environmental and economic] consequences".

Some environmental groups, such as the UK-based Global Commons Institute and the Worldwatch Institute, criticize what they call the vagueness of the analysis, its emphasis on economic factors, and its lack of concrete recommendations.

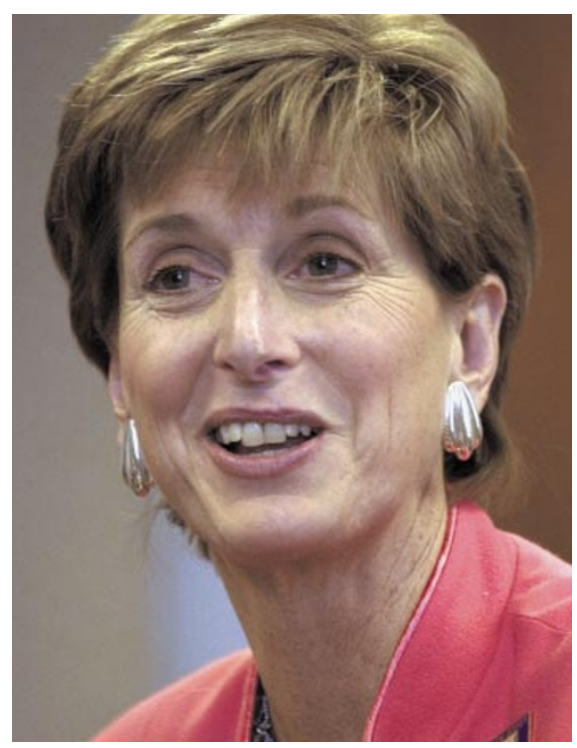

Rosy outlook: Christie Whitman says the US is serious about cutting greenhouse-gas emissions.

One observer close to administration discussions says that Colin Powell, the secretary of state, has been stressing the importance to US-EU relations of addressing climate change. It was on the agenda of his meeting this week with EU officials including Anna Lindh, Sweden's foreign minister. Sweden holds the EU presidency and has made global warming a priority.

Last month, US treasury secretary Paul O’Neill reportedly made a lengthy presentation to a cabinet meeting about the importance of tackling global climate change. Eileen Claussen, president of the non-profit Pew Center on Global Climate Change, where she worked closely with O'Neill, says he "believes it's a serious problem".

Claussen says that, despite the flurry of interest, the Bush administration still seems far from having fixed a strategy. But she finds the early activity promising, given the inattention she felt that climate change received in the last years of Bill Clinton's presidency.

A spokesperson for the European Commission in Washington agrees it is too early to tell what Bush's tack will be, but the commission hopes he "will share our sense of urgency in dealing with climate change". 